\title{
Effects and mechanism of STAT3 silencing on the growth and apoptosis of colorectal cancer cells
}

\author{
JING LI ${ }^{1}$, YOU-YU LIU ${ }^{2}$, XUE-FENG YANG ${ }^{3}$, DAO-FU SHEN ${ }^{3}$, HONG-ZHI SUN ${ }^{3}$, \\ KE-QIANG HUANG ${ }^{4}$ and HUA-CHUAN ZHENG ${ }^{3}$
}

\begin{abstract}
${ }^{1}$ Department of Gastroenterology, The First Affiliated Hospital of Jinzhou Medical University, Jinzhou, Liaoning 121001; ${ }^{2}$ Department of Orthopedics, The Central Hospital of Liaoyang, Liaoyang, Liaoning 111000; ${ }^{3}$ Tumor Basic and Translational Laboratory, The First Affiliated Hospital of Jinzhou Medical University; ${ }^{4}$ Department of

Orthodontics, School of Stomatology, Jinzhou Medical University, Jinzhou, Liaoning 121001, P.R. China
\end{abstract}

Received April 2, 2016; Accepted March 28, 2018

DOI: $10.3892 / \mathrm{ol} .2018 .9368$

\begin{abstract}
Signal transducer and activator of transcription 3 (STAT3) have roles in various cellular processes, including angiogenesis, apoptosis, cell cycle progression, cell migration and drug resistance. To clarify the effects of STAT3 in colorectal cancer (CRC) cells and the underlying molecular mechanisms, STAT3 was directly silenced, and the effects of STAT3 silencing on cell proliferation, apoptosis and growth with phenotype-associated molecules were examined. pSH1-Si-STAT3 was successfully transfected into the CRC HCT-116 and SW480 cell lines, which was verified by GFP tagging under a fluorescence microscope. An MTT assay revealed that the proliferation of both cell lines that were transfected with pSH1-Si-STAT3 was significantly suppressed in comparison with the control and mock $(\mathrm{P}<0.05)$. Acridine orange/ethidium bromide staining and flow cytometry indicated that the transfected cell lines had a significantly higher rate of apoptosis than the control- and mock-treated cells $(\mathrm{P}<0.05)$. STAT3-silienced cells were also significantly arrested at the $\mathrm{G}_{2} / \mathrm{M}$ stage compared with the cells that were transfected with control and mock plasmids $(\mathrm{P}<0.05)$. At the mRNA level, the expression of STAT3 and survivin was significantly downregulated $(\mathrm{P}<0.05)$, but $\mathrm{p} 53$ and caspase- 3 were significantly upregulated $(\mathrm{P}<0.05)$. The significantly different patterns of expression were observed in western blot analysis $(\mathrm{P}<0.05)$. The findings of the present study indicate that STAT3 silencing may suppress the proliferation and growth of CRC cells, and induce their apoptosis by upregulating the
\end{abstract}

Correspondence to: Professor Hua-Chuan Zheng, Tumor Basic and Translational Laboratory, The First Affiliated Hospital of Jinzhou Medical University, Renmin Road 5-2, Jinzhou, Liaoning 121001, P.R. China

E-mail: zheng_huachuan@hotmail.com

Key words: signal transducer and activator of transcription 3, silencing, colorectal cancer cells, proliferation, tumor growth, apoptosis, phenotype-associated genes expression of survivin, p53 and caspase-3. Therefore, STAT3 may be a good candidate for CRC gene therapy.

\section{Introduction}

Signal transducer and activator of transcription 3 (STAT3) is implicated in angiogenesis, apoptosis, cell-cycle progression, cell migration and drug resistance by regulating the expression of phenotype-associated genes $(1,2)$. Canonical STAT3-mediated signaling involves the phosphorylation of specific tyrosine residues that leads to homodimerization and translocation to the nucleus upon the stimulation of cytokines and growth factors $(3,4)$. Nuclear STAT3 fine-tunes autophagy by regulating the transcriptional expression of autophagy-associated genes and autophagy-targeting microRNAs, whereas its cytoplasmic counterpart constitutively suppresses autophagy by sequestering eukaryotic translation initiation factor $2-\alpha$ kinase 2 or interacting with forkhead box O (FOXO)1 and FOXO3 $(4,5)$. Additionally, STAT3 promotes mitochondrial transcription and oxidative respiration. The mitochondrial translocation of STAT3 serves a major role in IgE-antigen-mediated mast cell exocytosis and optimal electron transport chain activity, and protects against oxidative-stress-induced mitochondrial dysfunction and autophagy (6-8).

Although the levels of activated STAT3 remain transient in normal cells, it is overactive in $\sim 70 \%$ of human solid tumors and regulates the expression of numerous oncogenic genes that control the growth and metastasis of tumor cells (3). A meta-analysis revealed that elevated phosphorylated (p)-STAT3 levels are significantly associated with tumor cell differentiation, lymph node metastases and poor overall and disease-free survival rates inpatients with cancer of the digestive system (9). Janus kinase (JAK)-STAT3 signaling promotes oncogenesis by upregulating the proliferation, survival, invasion of tumor cells and immunosuppression (10). In recent years, antitumor approaches targeting STAT3 activity include the inhibition of tyrosine kinases or STAT3 dimer formation $(11,12)$. The present study directly silenced STAT3 and observed the effects on the proliferation and growth of colorectal cancer (CRC) cells. Additionally, the associated molecular mechanisms were also clarified. 


\section{Materials and methods}

Cell culture and transfection. HCT-116 and SW480 cells were obtained from the Cell Resource Center, Institute of Basic Medicine, Peking Union Medical University (Beijing, China) and grown in a humidified atmosphere with $5 \% \mathrm{CO}_{2}$ at $37^{\circ} \mathrm{C}$ in Dulbecco's modified Eagle's medium (DMEM) with 10\% fetal bovine serum (FBS; Corning Incorporated, Corning, NY, USA). Penicillin ( $100 \mathrm{U} / \mathrm{ml})$ and streptomycin $(100 \mu \mathrm{g} / \mathrm{ml})$ were added to the medium. All cells were collected by trypsinization at $37^{\circ} \mathrm{C}$ followed by centrifugation $(3,000 \mathrm{x} \mathrm{g}, 5 \mathrm{~min}$, room temperature), washed in phosphate buffered saline (PBS) and subjected to total RNA and protein extraction.

Either 1.0x10 $0^{6}$ HCT-116 or SW480 cells were transfected with pSilencer3.0-H1-STAT3-siRNA-GFP at $500 \mathrm{ng} / \mu \mathrm{l}$ (pSH1Si-STAT3 group) or pSH1Si-Scramble at $500 \mathrm{ng} / \mu 1$ (mock group) following seeding on dishes according to the manufacturer's instructions of Attractene Transfection Reagent (301005; Qiagen, Inc., Valencia, CA, USA). The untreated cells were used as control. After $2 \mathrm{~h}$ of transfection, cells were selected by G418 with the collection of monoclones, and immediately used for following proliferation assay, Acridine orange (AO)/ethidium bromide (EB) staining, PI staining and animal experiments were performed following transfection. The shRNA targets STAT3 nucleotides 2144-2162 (GenBank accession no. NM00315): Forward, 5'-GCAGCAGCTGAACAACAT GTTCAAGAGACATGTTGTTCAGCTGCTGCTTTTT-3' and reverse, 5'-AATTAAAAAGCAGCAGCTGAACAACATGTC TCTTGAACATGTTGTTCAGCTGCTGCTGCGGCC-3'.

Proliferation assay. HCT-116, SW480 and pSH1SiSTAT3-transfected cells were seeded at $2.0 \times 10^{3}$ cells per well in 96-well plates and maintained in media containing $10 \%$ FBS. At $0,24,48$ and $72 \mathrm{~h}$, the cells then were incubated with $20 \mu \mathrm{l}$ MTT $(5 \mathrm{mg} / \mathrm{ml})$ for $4 \mathrm{~h}$ at $37^{\circ} \mathrm{C}$. The medium was then discarded and $150 \mu \mathrm{l}$ dimethyl sulfoxide was added to each well to dissolve the precipitates. The number of viable cells was counted by measuring the absorbance at $490 \mathrm{~nm}$ using a microplate reader. The experiment was repeated three times.

$A O / E B$ staining. $\mathrm{AO}$ is a nucleic-acid-selective fluorescent cationic dye that can pass through live and dead cells. Upon treatment with the two reagents, live cells appear uniformly green under a fluorescence microscope, whereas apoptotic cells stain green and bright green dots appear in the nuclei. Necrotic cells stain orange under a fluorescence microscope. EB can only stain cells that have lost membrane integrity. In brief, HCT-116, SW480, pSH1Si-Scramble- and pSH1Si-STAT3-transfected cells were resuspended in an AO solution at $1 \times 10^{10}$ cells/l. A total of $2 \mu \mathrm{l}$ AO solution $(100 \mathrm{mg} / \mathrm{ml})$ and $2 \mu \mathrm{l} \mathrm{EB}$ solution $(100 \mathrm{mg} / \mathrm{ml})$ were added into $20 \mu \mathrm{l}$ cells for $5 \mathrm{~min}$ at room temperature. Next, the cells were seeded onto glass slides and observed in 5 fields under a fluorescence microscope (x200 magnification).

Flow cytometry. HCT-116 and SW480, pSH1Si-Scramble- and pSH1Si-STAT3-transfected cells were washed twice with PBS then detached by trypsinization with free EDTA. The cells were collected in a centrifuge tube and incubated with
$1 \mathrm{ml}$ precooled $70 \%$ ethanol for $\geq 12 \mathrm{~h}$. The cells were washed twice with PBS again and incubated for $1 \mathrm{~h}$ at $37^{\circ} \mathrm{C}$ with $1 \mathrm{ml}$ RNase $(0.25 \mathrm{mg} / \mathrm{ml}$, Sigma-Aldrich, Merck KGaA, Darmstadt, Germany). The cells were resuspended in propidium iodide (PI) at a concentration of $50 \mu \mathrm{g} / \mathrm{ml}$, and cell cycle analysis was performed using a flow cytometer with CytExpert software (version 2.0; Beckman Coulter, Inc., Brea, CA, USA) used for analysis.

Xenograft models. A total of 15 male BALB/c nude mice of 6-8 weeks $(17.76 \pm 1.83 \mathrm{~g})$ were kept in a specific pathogen-free facility in a temperature-controlled animal room $\left(22-24^{\circ} \mathrm{C}\right)$ with a 12/12 h light/dark illumination cycle. All of the mice had access to standard rodent food (Beijing Huafukang Biotech Co., Ltd., Beijing, China) and water ad libitum. All animal treatments were performed in accordance with international ethics guidelines and the National Institutes of Health Care and Use of Laboratory Animals. This study was approved by the Institutional Animal Care and Use Committee of The First Affiliated Hospital of Jinzhou Medical University (Jinzhou, China).

HCT-116, pSH1Si-Scramble- and pSH1Si-STAT3-transfected cells were grown in the medium as aforementioned. The cells were detached by trypsinization, and subsequently washed and resuspended in DMEM medium. Subcutaneous xenografts were established by injection of $1.0 \times 10^{7}$ HCT-116 cells/mouse ( $\mathrm{n}=5 /$ group), and the mice were assessed every 4 days for tumor size and body weight. The model was established successfully when there were nodules with the size of a grain of rice after 1week and a volume of $50-70 \mathrm{~mm}^{3}$ after 2 weeks.

The nude mice were divided into control, mock and treatment groups, and each group consisted of 5 mice. The treatment volume was $40 \mu \mathrm{l}$, and the plasmid concentration was $0.5 \mu \mathrm{g} / \mu \mathrm{l}$, which was injected intratumorally at several points. At $30 \mathrm{sec}$ after injection, an electrical impulse was applied twice at intervals of $>1 \mathrm{~min}$. Electrodes were placed at each end of the tumor's long and short axes (electric field strength, $200 \mathrm{~V} / \mathrm{cm}$; electric pulse duration, $50 \mathrm{msec}$ and pulse frequency, $1 \mathrm{~Hz}$ ). This process was repeated on days 10 and 17. Tumor volume and mouse body weight were measured every 4 days. On day 20 , the tumors were removed, and the tumor weight and volume were measured. Tumor growth was calculated as follows: Length $\mathrm{x}$ width ${ }^{2} \mathrm{x} 0.52$. At the end of the experiment, the mice from each group were anesthetized, their images were captured and the mice were sacrificed. The tumors were weighed and subjected to RNA or protein extraction for subsequent experiments.

Reverse transcriptase-polymerase chain reaction (RT-PCR). Total RNA was isolated from CRC cells or tissues using TRIzol (Takara Bio, Inc., Otsu, Japan) and quantified using a NanoDrop spectrophotometer (NanoDrop Technologies; Thermo Fisher Scientific, Inc., Wilmington, DE USA). RT-PCR was performed with $2 \mu \mathrm{g}$ total RNA using AMV reverse transcriptase and random primers at $42^{\circ} \mathrm{C}$ for $1 \mathrm{~h}$ (Takara Bio, Inc.). PCR primers were designed and are listed in Table I. The amplification of cDNA was performed using the Hot Start Taq Polymerase kit (Takara Bio, Inc.) with GAPDH as an internal control. The PCR conditions were as follows: Denaturation 
Table I. Primers used for reverse transcription-semi-quantitative polymerase chain reaction.

\begin{tabular}{|c|c|c|c|c|}
\hline Gene & Primer sequence & $\mathrm{AT}\left({ }^{\circ} \mathrm{C}\right)$ & Product size (bp) & Extension time (sec) \\
\hline STAT3 & & 55 & 315 & 30 \\
\hline Forward & 5'-TTGCCAGTTGTGGTGATC-3' & & & \\
\hline Reverse & 5'-AGACCCAGAAGGAGCCGC-3' & & & \\
\hline \multicolumn{5}{|l|}{ Survivin } \\
\hline Forward & 5'GAATTCATGGGTGCCCCGACCTTGCC-3' & 58 & 412 & 30 \\
\hline Reverse & 5'-AGATCTTTCTTCTTATTGTTGGTTTCC-3' & & & \\
\hline Caspase-3 & & 55 & 241 & 30 \\
\hline Forward & 5'-AGAACTGGACTGTGGCATTG-3' & & & \\
\hline Reverse & 5'-TTCTGTTGCCACCTTTCG-3' & & & \\
\hline \multicolumn{5}{|l|}{$\beta$-actin } \\
\hline Forward & 5'-AAGTACTCCGTGTGGATCGG-3' & & & \\
\hline Reverse & 5'-ATGCTATCACCTCCCCTGTG-3' & 55 & 600 & 30 \\
\hline
\end{tabular}

AT, annealing temperature; STAT3, signal transducer and activator of transcription 3.

at $95^{\circ} \mathrm{C}$ for $10 \mathrm{~min}$; followed by 30 cycles of denaturation at $95^{\circ} \mathrm{C}$ for $15 \mathrm{sec}$, annealing at $55^{\circ} \mathrm{C}$ for $30 \mathrm{sec}$ and extension at $72^{\circ} \mathrm{C}$ for $30 \mathrm{sec}$; and as a termination step, the extension time of the last cycle was increased to $7 \mathrm{~min}$. The amplicons were electrophoresed in $2 \%$ agarose and visualized under UV light. Densitometric quantification was performed with $\beta$-actin as a control using ImageJ version 1.48 (National Institutes of Health, Bethesda, MD, USA). The value of the control was set to 1 .

Western blot analysis. Protein extraction was performed from gastric carcinoma and epithelial cells or carcinoma tissues by sonication or homogenization in radioimmunoprecipitation assay lysis buffer [50 mM Tris- $\mathrm{HCl}(\mathrm{pH} 7.5), 150 \mathrm{mM}$ $\mathrm{NaCl}, 5 \mathrm{mM}$ EDTA, 0.5\% Nonidet P-40 (Sigma-Aldrich; Merck $\mathrm{KGaA}$ ), $5 \mathrm{mM}$ dithiothreitol, $10 \mathrm{mM} \mathrm{NaF}$ and protease inhibitor cocktail (Nacalai Tesque, Inc., Kyoto, Japan)]. A total of $40 \mu \mathrm{g}$ protein was measured and calculated according to Kaumas brilliant blue method (13) from HCT-116, SW480 and pSH1Si-STAT3-transfected cells, and tumors of HCT-116 and pSH1Si-STAT3-transfected cells per lane. The protein samples were resolved using 10\% SDS-PAGE and transferred to a polyvinylidene fluoride membrane. The membrane was blocked with 5\% skimmed milk in Tris-buffered saline with Tween 20 (TBST; 10 mM Tris-HCl, 150 mM NaCl, 0.1\% Tween 20) for $1 \mathrm{~h}$ at room temperature, and the primary antibodies were placed on a shaker at $4^{\circ} \mathrm{C}$ overnight. The antibodies against $\beta$-actin (sc-47778; 1:1,000), p-STAT3 (sc-56747; 1:500), STAT3 (sc-293151; 1:500), surviving (sc-101433; 1:500), tumor protein p53 (sc-47698; 1:500) and caspase-3 (sc-136219; 1:500) were purchased from Santa Cruz Biotechnology, Inc. (Dallas, TX, USA). The cells were rinsed with TBST and incubated with IgG antibody that was conjugated to horseradish peroxidase (HRP; Dako, Carpinteria CA, USA) at a dilution of 1:1,000 at room temperature for $1 \mathrm{~h}$. The bands were visualized using LAS4010 (GE Healthcare Life Sciences, Little Chalfont, USA) and ECL-Plus detection reagents (Santa Cruz Biotechnology, Inc., Dallas, TX, USA). The experiment was repeated for three times. Densitometric quantification was performed with $\beta$-actin as a control using ImageJ version 1.48 . The control was considered to have a value of ' 1 '.

Statistical analysis. The results are expressed as mean \pm standard deviation. Statistical evaluation was performed using Kruskal-Wallis to compare the means of different groups. $\mathrm{P}<0.05$ was considered to indicate statistical significance. SPSS 10.0 software (SPSS, Inc., Chicago, IL, USA) was used to analyze all data.

\section{Results}

Effects and associated mechanisms of STAT3 silencing on the proliferation and apoptosis of CRC cells. pSH1-Si-STAT3 and pSH1Si-Scramble were successfully transfected into CRC cells as indicated by the findings from fluorescence microscopy (Fig. 1A). The effect of STAT3 silencing on the viability of HCT-116 and SW480 cells was assessed using an MTT assay. As shown in Fig. 1B, the proliferation of the two cell lines transfected with the pSH1-siRNA-STAT3 plasmid was significantly suppressed $48 \mathrm{~h}$ after transfection compared with the control and pSH1Si-scramble groups $(\mathrm{P}<0.05)$. There was a significantly higher rate of apoptosis in CRC cells that were treated with the pSH1-siRNA-STAT3 plasmids than those in the control and mock groups as indicated by $\mathrm{AO} / \mathrm{EB}$ and $\mathrm{PI}$ staining $(\mathrm{P}<0.05$; Fig. $1 \mathrm{C}$ and $\mathrm{D})$. Cell cycle analysis revealed a significantly higher proportion of STAT3-silenced cells in $\mathrm{G}_{2}$ /M-phase arrest compared with the control and mock groups $(\mathrm{P}<0.05$; Fig. $1 \mathrm{E}$ and $\mathrm{F})$. The mRNA levels of STAT3 and survivin were significantly decreased in all cells and tumor tissues, but the expression of p53 and caspase-3 mRNA was significantly increased in the pSH1-siRNA-STAT3 group, compared with the control and mock plasmid groups $(\mathrm{P}<0.05$; Fig. 1G). Western blot analysis revealed that the expression of p-STAT3, STAT3 and survivin was significantly lower in cells that were transfected with pSH1-siRNA-STAT3, compared with the control- and mock 
A

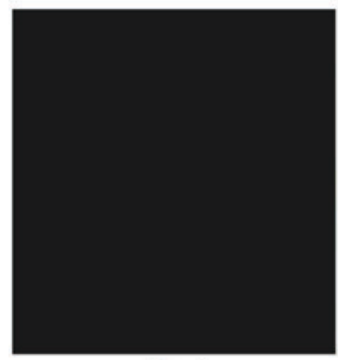

Mock

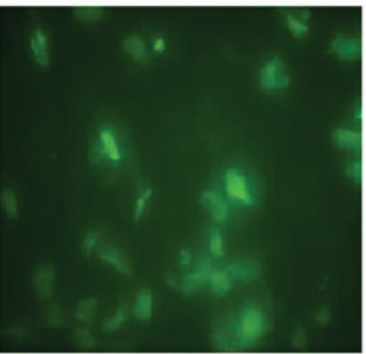

pSHISI-STAT3
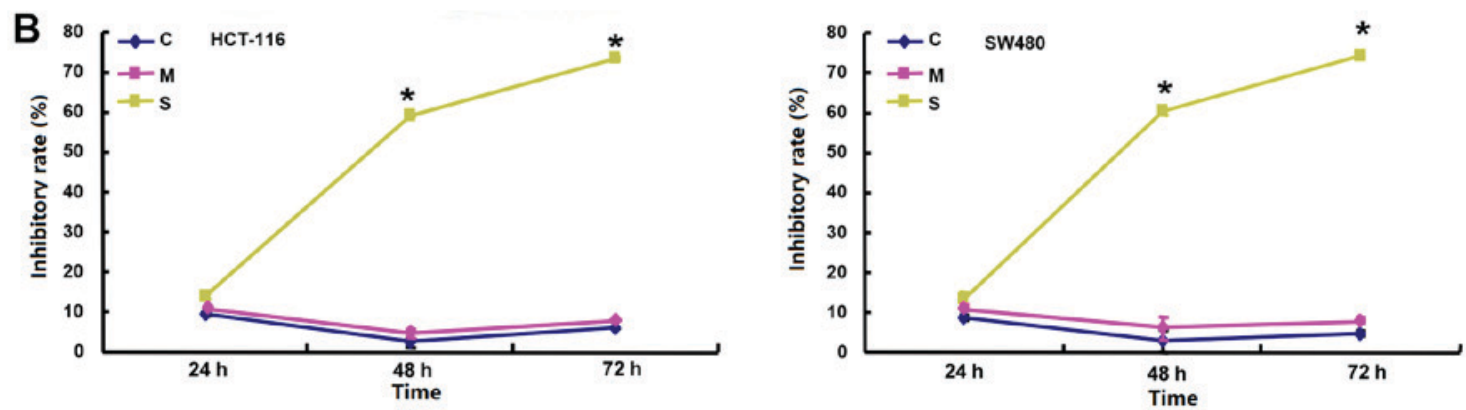

C

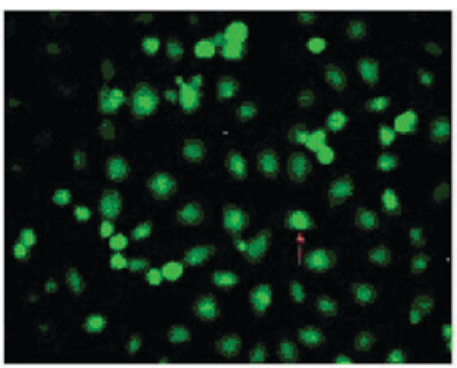

C

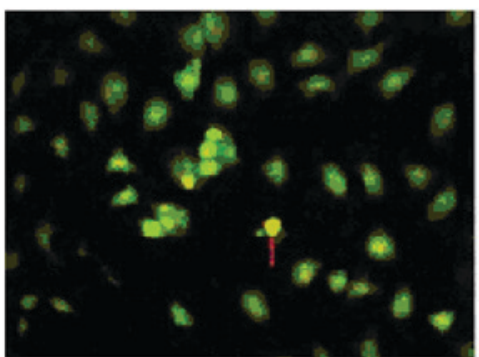

M

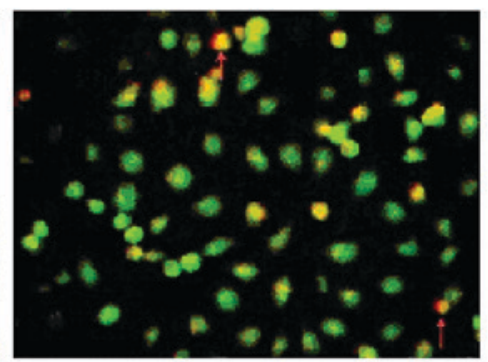

S $\overline{20, m}$
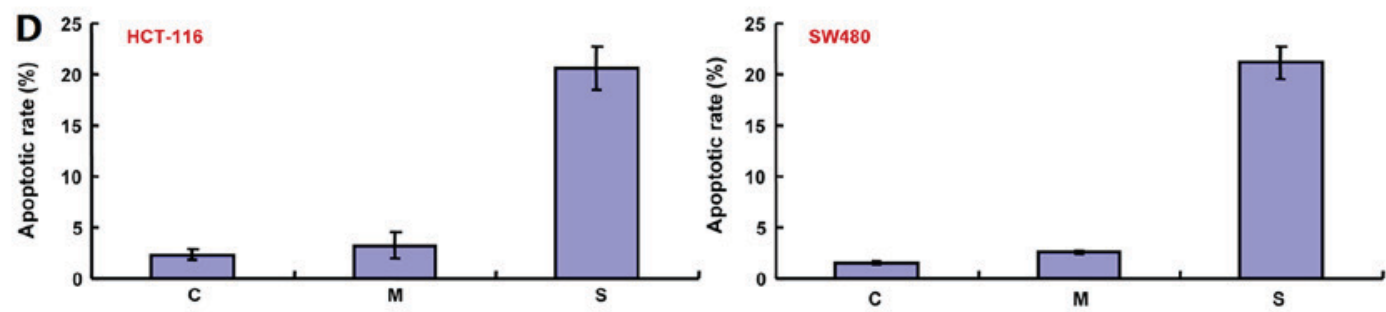

E
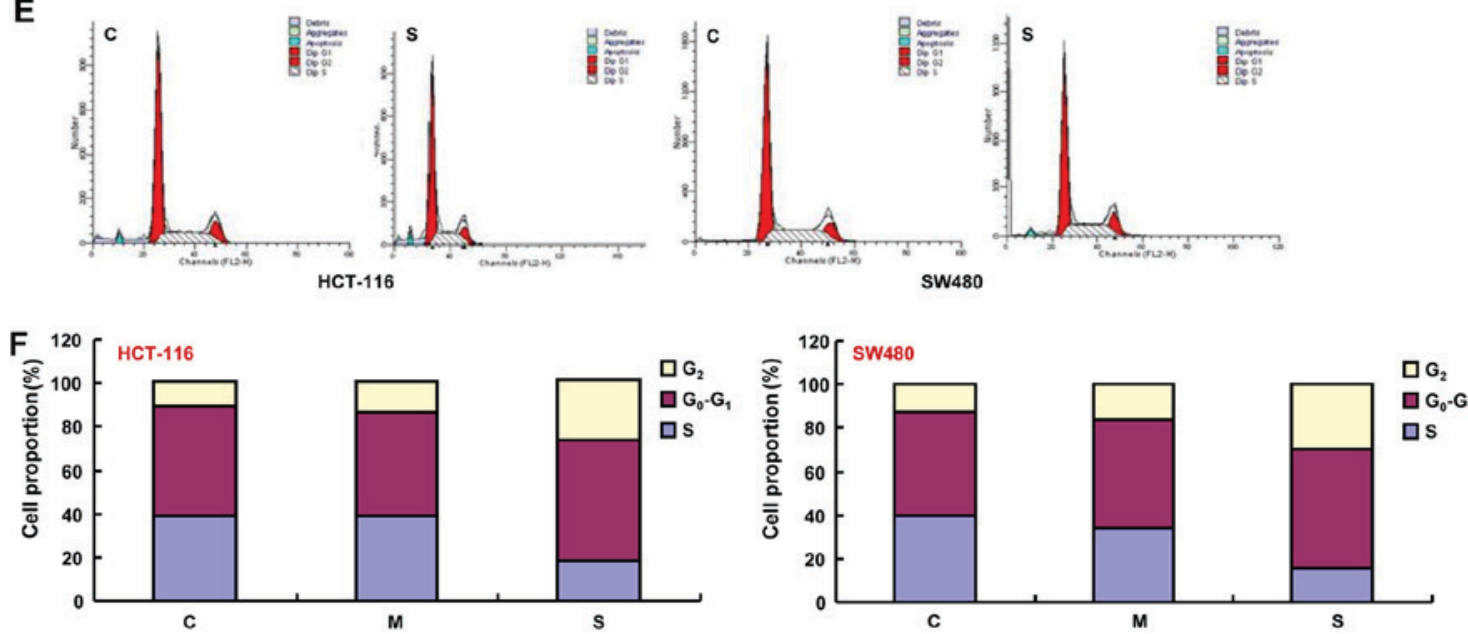

Figure 1. Effects and associated mechanisms of STAT3 silencing on proliferation and apoptosis of colorectal cancer cells. (A) Following transfection of pSH1Si-STAT3, GFP expression was observed under a fluorescence microscope. (B) The cells that were transfected with pSH1Si-STAT3 exhibited a lower growth rate compared with the control and mock cells as assessed by MTT assay. There appeared to be a higher degree of apoptosis in cells that were transfected with the pSH1Si-STAT3 plasmid than the control and mock cells as indicated by (C) acridine orange/ethidium bromide and (D) statistical analysis of apoptotic number. STAT3 silencing could induce $\mathrm{G}_{2} / \mathrm{M}$ arrest of HCT-116 and SW480 transfectants as indicated by (E) PI staining and (F) statistical analysis of cell proportion. ${ }^{*} \mathrm{P}<0.05$ compared with the control and mock 
G
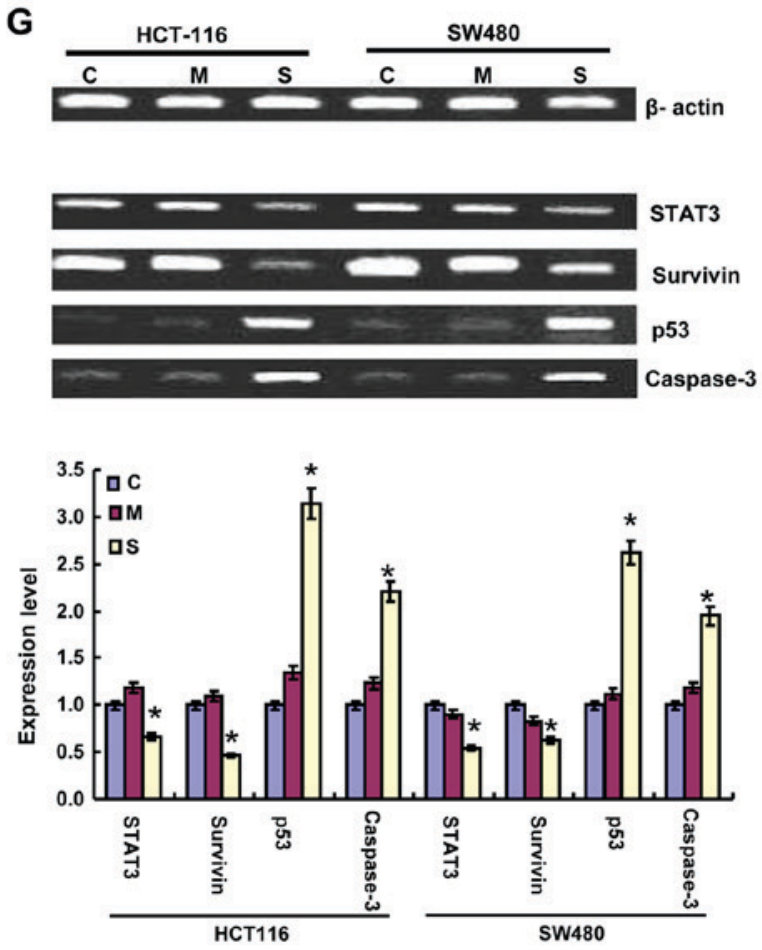

H
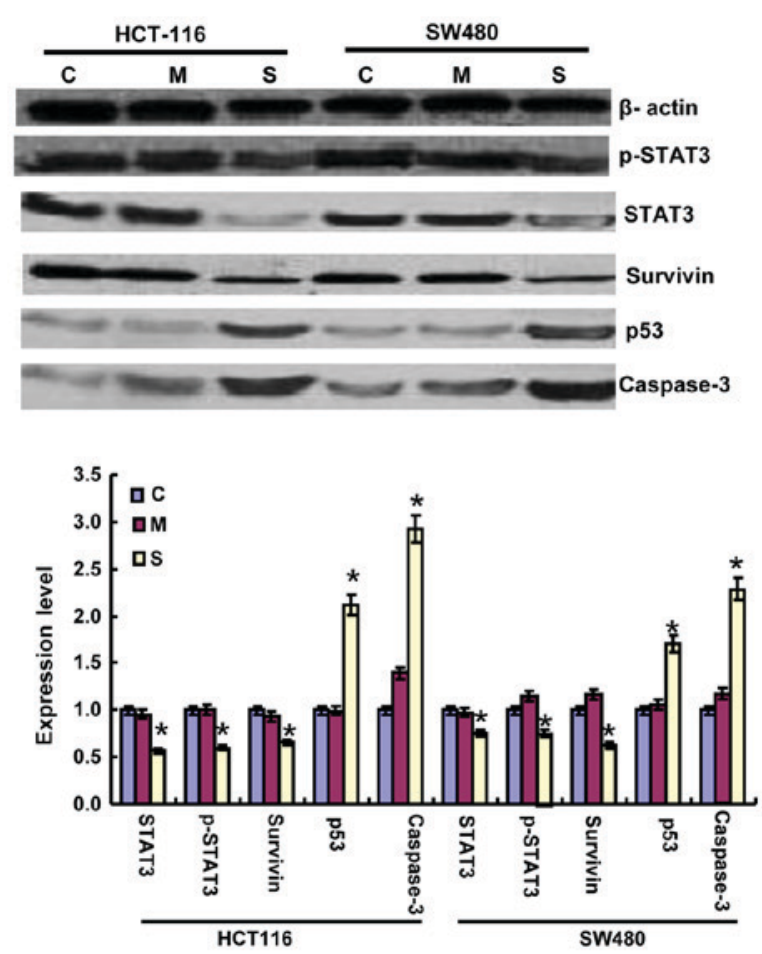

Figure 1. Continued. The phenotype-associated molecules were screened by (G) reverse-transcription-semi-quantitative polymerase chain reaction and (H) western blot analysis. "P $<0.05$ compared with the control or mock. p-, phosphorylated; STAT3, signal transducer and activator of transcription 3; C, control; $\mathrm{M}$, mock (pSH1Si-Scramble); S, pSH1Si-STAT3; * $<<0.05$, compared with control or mock.

plasmid-transfected groups, but the opposite was true for $\mathrm{p} 53$ and caspase- $3(\mathrm{P}<0.05$; Fig. $1 \mathrm{H})$.

Effects and associated mechanisms of STAT3 silencing on tumor growth of CRC cells. The volume and weight of the mouse tumors in the pSH1-siRNA-STAT3 group were significantly smaller and lower compared with the controland mock plasmid-transfected groups $(\mathrm{P}<0.05$; Fig. 2A-C). The longest diameter of a single subcutaneous tumor was $11.2 \mathrm{~mm}$ in the present study. The mRNA levels of STAT3 and survivin were significantly decreased in all cells and tumor tissues, but the expression of p53 and caspase-3 mRNA was significantly increased in the pSH1-siRNA-STAT3 group, compared with the control and mock plasmid groups $(\mathrm{P}<0.05$; Fig. 2D). Western blot analysis revealed that the expression of p-STAT3, STAT3 and survivin was significantly lower in cells that were transfected with pSH1-siRNA-STAT3, compared with the control- and mock plasmid-transfected groups, but the opposite was true for p53 and caspase-3 (P<0.05; Fig. 2E).

\section{Discussion}

Increased STAT3 activity is common in human malignancies, including CRC. Reportedly, p-STAT3 immunoreactivity gradually increases from normal mucosa to adenoma to adenocarcinoma. p-STAT3 immunoreactivity is positively associated with the $\mathrm{T}$ stage and clinical stage of CRC. In a previous study involving the analysis of 47 invasive colorectal adenocarcinoma samples, STAT3 mRNA expression was significantly associated with tumor size, lymph node and metastasis stage and clinical stage of the disease (9). In CRC, nuclear p-STAT3 protein expression was associated with the expression of its target genes B-cell lymphoma-extra large $(\mathrm{Bcl}-\mathrm{xL})$ and survivin as well as $\mathrm{Ki}-67$. The inactive (UP-STAT3) and active (p-STAT3) STAT3 proteins are markedly increased in invasive CRC cases. This increase is associated with Bcl-xL and survivin induction, increased proliferation and lymph node metastasis $(9,14,15)$. These findings indicate that STAT3 activation contributes to colorectal carcinogenesis and subsequent disease progression. In the present study, STAT3 knockdown significantly suppressed cell proliferation and tumor growth, and induced apoptosis and $\mathrm{G}_{2} / \mathrm{M}$ arrest in HCT-116 and SW480 cells, suggesting that STAT3 could be employed as a potential target of gene therapy for patients with CRC.

Hypoxia-inducible factor $3 \alpha 1$ and miR-139-5p deletion promote the growth of CRC cells by activating the JAK-STAT3 signaling pathway $(16,17)$. The insulin-like growth factor/STAT3/NANOG/Slug and interleukin-6/STAT3/Fos-related antigen-1 signaling axes simultaneously control epithelial-mesenchymal transition and maintenance of stemness in CRC, which exhibit drug resistance, invasion and metastasis $(18,19)$. It was documented that STAT3 inhibition sensitized CRC to chemoradiotherapy in vitro and in vivo. Furthermore, the overexpression of STAT3 was associated with the resistance of CRC cells to 5-fluorouracil-based chemoradiotherapy $(20,21)$. The inhibition of DNA methyltransferase by miR-124 and miR-874 was demonstrated to suppress growth and induce apoptosis in CRC by targeting STAT3, where STAT3 is often hyper-activated (22-24). The overexpression of $\mathrm{B} 7-\mathrm{H} 3$ was able to induce resistance to apoptosis in CRC cell lines by upregulating the Jak2-STAT3 signaling pathway, whereas suppressor of cytokine signaling 3 served as a negative regulator of the JAK-STAT3 pathway to 
A
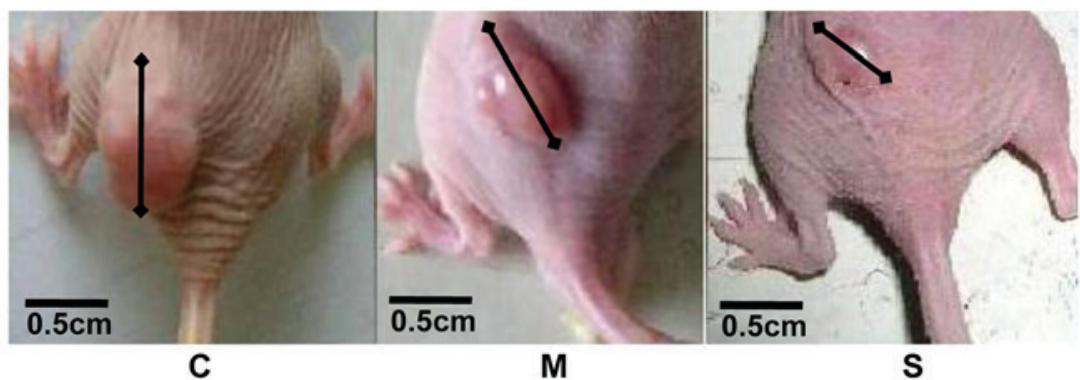

B
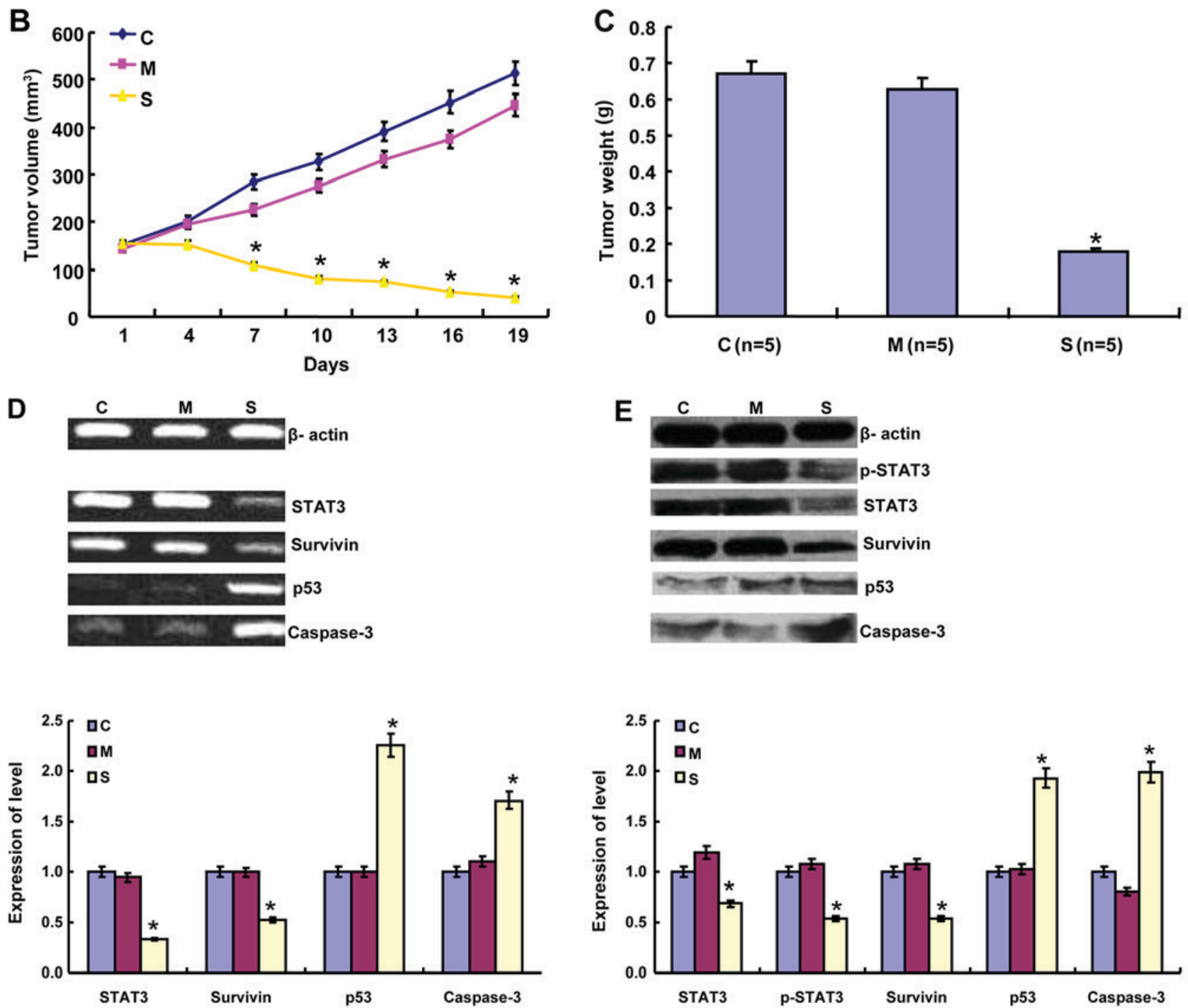

Figure 2. Effects and associated mechanisms of STAT3 silencing on tumor growth of colorectal cancer cells. (A) There existed tumor in the back of nude mice in control, mock and STAT3-knockdown groups. (B) The growth of HCT-116 and mock cells was faster than pSH1Si-STAT3 tranfectants as shown by tumor volume (C). The tumor weight was lighter in STAT3-knockdown group compared with the control and mock groups. (D) Western blotting analysis and (E) reverse transcription-semi-quantitative polymerase chain reaction were performed to detect the phenotype-related molecules. " $\mathrm{P}<0.05$, compared with the control or mock-transfected tumor cells. p-, phosphorylated; STAT3, signal transducer and activator of transcription 3; C, control; M, mock-pSH1Si-Scramble; S, pSH1Si-STAT3; "P $<0.05$, compared with control and mock.

suppress cell proliferation and cell cycle (25-27). In addition, the epidermal growth factor/phosphoinositide-3 kinase/STAT3 signaling pathway enhanced the expression of angiogenic regulators, including vascular endothelial growth factor and leptin. The inhibition of STAT3 was able to suppress angiogenesis in CRC $(28,29)$. These data underlie the molecular basis of gene and drug therapies targeting STAT3.
In the present study, following STAT3 knockdown, the levels of p-STAT3 and STAT3 were downregulated in HCT-116 and SW480 cells or tumors, indicating that the transfections were effective. To clarify the molecular mechanisms, the expression of survivin, p53 and caspase- 3 at mRNA and protein levels was detected. The silencing of STAT3 was able to markedly decrease survivin expression, but the expression 
of p53 and caspase-3 was increased. Survivin is an oncogene that has been implicated in several types of human cancer. Survivin protein ameliorates caspase activation to negatively regulate apoptosis or programmed cell death and localizes to the mitotic spindle by interacting with tubulin during mitosis to modulate mitosis (30). Caspase-3 is activated in apoptotic cells by extrinsic (death ligands) and intrinsic (mitochondrial) pathways, which results in the cleavage of poly (ADP-ribose) polymerase, actin and the sterol regulatory element binding protein (31). p53 protects against the development of cancer, including the induction of apoptosis, cell cycle arrest and the maintenance of genetic stability (32). Taking the results of the present study together, it was concluded that STAT3 promoted the proliferation and growth of CRC cells and suppressed apoptosis by targeting the expression of survivin, p53 and caspase- 3 and could therefore be considered to be a potential target for gene therapy.

In conclusion, the silencing expression of STAT3 in vitro and in vivo may have a therapeutic effect in CRC cells, which brings hope of clinical therapy using RNA interference via oligonucleotide drugs. Future study will continue to investigate the synergistic effects of STAT3-knockdown and other therapeutic approaches to inhibit the proliferation and induce the apoptosis of CRC cells.

\section{Acknowledgements}

Not applicable.

\section{Funding}

The present study was supported by the Liaoning Bai Qian Wan Talents Program, the Scientific Research Fund of Liaoning Provincial Education Department (grant no. LJQ2014093), Outstanding Scientific Fund of Shengjing Hospital, Award for Liaoning Distinguished Professor, Shenyang Science and Technology Grand (grant no. 18-013-0-59), the Key Scientific and Technological Project of Liaoning Province (grant nos. 2015408001, 20101064 and 2013225305) and the National Natural Scientific Foundation of China (grant nos. 81472544 and 81672700).

\section{Availability of data and materials}

The datasets used and/or analyzed during the present study are available from the corresponding author on reasonable request.

\section{Authors' contributions}

JL, XFY, DFS, YYL, HZS, KQH and HCZ designed the study, performed the experiment and statistical analysis. JL, KQH and HCZ prepared reviewed the manuscript. All the authors read the manuscript, took responsibility for all aspects of the work and approved the manuscript published without conflict of interest.

\section{Ethics approval and consent to participate}

The ethics of animal performance protocol was approved by Institutional Animal Care and Use Committee of The First
Affiliated Hospital of Jinzhou Medical University (Jinzhou, China).

\section{Patient consent for publication}

Not applicable.

\section{Competing interests}

The authors declare that they have no competing interests.

\section{References}

1. Wake MS and Watson CJ: STAT3 the oncogene-still eluding therapy? FEBS J 282: 2600-2611, 2015.

2. Zhao C, Li H, Lin HJ, Yang S, Lin J and Liang G: Feedback activation of STAT3 as a cancer drug-resistance mechanism. Trends Pharmacol Sci 37: 47-61, 2016.

3. Bromberg JF, Wrzeszczynska MH, Devgan G, Zhao Y, Pestell RG, Albanese C and Darnell JE Jr: Stat3 as an oncogene. Cell 98: 295-303, 1999.

4. Srivastava J and DiGiovanni J: Non-canonical Stat3 signaling in cancer. Mol Carcinog 55: 1889-1898, 2016.

5. You L, Wang Z, Li H, Shou J, Jing Z, Xie J, Sui X, Pan H and Han W: The role of STAT3 in autophagy. Autophagy 11: 729-739, 2015.

6. Yu H, Lee H, Herrmann A, Buettner R and Jove R: Revisiting STAT3 signaling in cancer: New and unexpected biological functions. Nat Rev Cancer 14: 736-746, 2014.

7. Carbognin E, Betto RM, Soriano ME, Smith AG and Martello G: Stat 3 promotes mitochondrial transcription and oxidative respiration during maintenance and induction of naive pluripotency. EMBO J 35: 618-634, 2016

8. Erlich TH, Yagil Z, Kay G, Peretz A, Migalovich-Sheikhet H, Tshori S, Nechushtan H, Levi-Schaffer F, Saada A and Razin E: Mitochondrial STAT3 plays a major role in IgE-antigen-mediated mast cell exocytosis. J Allergy Clin Immunol 134: 460-469, 2014

9. Park JK, Hong R, Kim KJ, Lee TB and Lim SC: Significance of p-STAT3 expression in human colorectal adenocarcinoma. Oncol Rep 20: 597-604, 2008.

10. Ferguson SD, Srinivasan VM and Heimberger AB: The role of STAT3 in tumor-mediated immune suppression. J Neurooncol 123: 385-394, 2015.

11. Furtek SL, Backos DS, Matheson CJ and Reigan P: Strategies and approaches of targeting STAT3 for cancer treatment. ACS Chem Biol 11: 308-318, 2016 .

12. Chai EZ, Shanmugam MK, Arfuso F, Dharmarajan A, Wang C, Kumar AP, Samy RP, Lim LH, Wang L, Goh BC, et al: Targeting transcription factor STAT3 for cancer prevention and therapy. Pharmacol Ther 162: 86-97, 2016.

13. Zhao Y, Chen S, Gou WF, Niu ZF, Zhao S, Xiao LJ, Takano Y and Zheng HC: The role of EMMPRIN expression in ovarian epithelial carcinomas. Cell Cycle 12: 2899-2913, 2013.

14. Lassmann S, Schuster I, Walch A, Göbel H, Jütting U, Makowiec F, Hopt U and Werner M: STAT3 mRNA and protein expression in colorectal cancer: Effects on STAT3-inducible targets linked to cell survival and proliferation. J Clin Pathol 60: $173-179,2007$.

15. Ma XT, Wang S, Ye YJ, Du RY, Cui ZR and Somsouk M: Constitutive activation of Stat 3 signaling pathway in human colorectal carcinoma. World J Gastroentero 10: 1569-1573, 2004.

16. Xue X, Jungles K, Onder G, Samhoun J, Győrffy B and Hardiman KM: HIF-3 $\alpha 1$ promotes colorectal tumor cell growth by activation of JAK-STAT3 signaling. Oncotarget 7: 11567-11579, 2016.

17. Zou F, Mao R, Yang L, Lin S, Lei K, Zheng Y, Ding Y, Zhang P, Cai G, Liang $X$ and Liu J: Targeted deletion of miR-139-5p activates MAPK, NF- $\mathrm{KB}$ and STAT3 signaling and promotes intestinal inflammation and colorectal cancer. FEBS J 283: 1438-1452, 2016.

18. Yao C, Su L, Shan J, Zhu C, Liu L, Liu C, Xu Y, Yang Z, Bian X, Shao J, et al: IGF/STAT3/NANOG/Slug signaling axis simultaneously controls epithelial-mesenchymal transition and stemness maintenance in colorectal cancer. Stem Cells 34: 820-831, 2016. 
19. Liu H, Ren G, Wang T, Chen Y, Gong C, Bai Y, Wang B, Qi H, Shen J, Zhu L, et al: Aberrantly expressed Fra-1 by IL-6/STAT3 transactivation promotes colorectal cancer aggressiveness through epithelial-mesenchymal transition. Carcinogenesis 36: $459-468,2015$

20. Spitzner M, Roesler B, Bielfeld C, Emons G, Gaedcke J, Wolff HA, Rave-Fränk M, Kramer F, Beissbarth T, Kitz J, et al: STAT3 inhibition sensitizes colorectal cancer to chemoradiotherapy in vitro and in vivo. Int J Cancer 134: 997-1007, 2014.

21. Fan LC, Teng HW, Shiau CW, Tai WT, Hung MH, Yang SH, Jiang JK and Chen KF: Pharmacological targeting SHP-1-STAT3 signaling is a promising therapeutic approach for the treatment of colorectal cancer. Neoplasia 17: 687-696, 2015.

22. Xiong H, Chen ZF, Liang QC, Du W, Chen HM, Su WY, Chen GQ, Han ZG and Fang JY: Inhibition of DNA methyltransferase induces G2 cell cycle arrest and apoptosis in human colorectal cancer cells via inhibition of JAK2/STAT3/STAT5 signalling. J Cell Mol Med 13: 3668-3679, 2009.

23. Zhao B and Dong AS: MiR-874 inhibits cell growth and induces apoptosis by targeting STAT3 in human colorectal cancer cells. Eur Rev Med Pharmacol Sci 20: 269-277, 2016.

24. Zhang J, Lu Y, Yue X, Li H, Luo X, Wang Y, Wang K and Wan J: MiR-124 suppresses growth of human colorectal cancer by inhibiting STAT3. PLoS One 8: e70300, 2013.

25. Liu F, Zhang T, Zou S, Jiang B and Hua D: B7-H3 promotes cell migration andinvasion through the Jak2/Stat3/MMP9 signaling pathway in colorectal cancer. Mol Med Rep 12: 5455-5460, 2015

26. Zhang T, Jiang B, Zou ST, Liu F and Hua D: Overexpression of B7-H3 augmentsanti-apoptosis of colorectal cancer cells by Jak2-STAT3. World J Gastroenterol 21: 1804-1813, 2015.
27. Wei X, Wang G, Li W, Hu X, Huang Q, Xu K, Lou W, Wu J, Liang C, Lou Q, et al: Activation of the JAK-STAT3 pathway is associated with the growth of colorectal carcinoma cells. Oncol Rep 31: 335-341, 2014

28. Qian WF, Guan WX, Gao Y, Tan JF, Qiao ZM, Huang H and Xia CL: Inhibition of STAT3 by RNA interference suppresses angiogenesis in colorectal carcinoma. Braz J Med Biol Res 44: 1222-1230, 2011

29. Cascio S, Ferla R, D'Andrea A, Gerbino A, Bazan V, Surmacz E and Russo A: Expression of angiogenic regulators, VEGF and leptin, is regulated by the EGF/PI3K/STAT3 pathway in colorectal cancer cells. J Cell Physiol 221: 189-194, 2009.

30. Soleimanpour E and Babaei E: Survivin as a potential target for cancer therapy. Asian Pac J Cancer Prev 16: 6187-6191, 2015.

31. Xiao LJ, Zhao S, Zhao EH, Zheng X, Gou WF, Takano Y and Zheng HC: Clinicopathological and prognostic significance of $\mathrm{Ki}-67$, caspase-3 and p53 expression in gastric carcinomas. Oncol Lett 6: 1277-1284, 2013.

32. Wang X, Simpson ER and Brown KA: p53: Protection against tumor growth beyond effects on cell cycle and apoptosis. Cancer Res 75: 5001-5007, 2015.

This work is licensed under a Creative Commons

Attribution-NonCommercial-NoDerivatives 4.0 International (CC BY-NC-ND 4.0) License. 